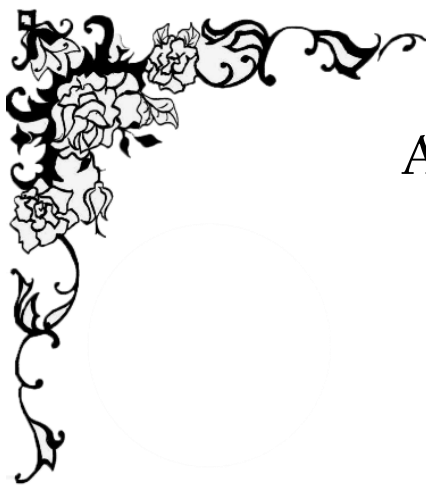

\title{
TREND OF HALAL TOURISM AS A LIVING QUR'AN PRACTICE IN LOMBOK
}

\author{
Siti Maryam \\ Pasca Sarjana Universitas Islam Negeri Sunan Kalijaga, Yogyakarta \\ Bintiruslan4@gmail.com
}

Abtract - The trend of halal tourism is not only seen as an effort to develop the economy of an area, but also the concept of making Muslim tourists comfortable when carrying out tourism activities, by providing adequate worship facilities, water availability, halal food in restaurant and hotel, prevention of practice immoral and others. This atricle wil focus on: (1) how the concept of halal tourism; (2) what factors cause halal tourism to be developed; (3) how halal tourism affects religiosity and increases the economic welfare of the region. This research found that the concept of halal tourism is very important to continue to be developed, because it is a practice of reviving the Qur'an (living Qur'an) in tourism activities. In addition, halal tourism is also a manifestation of hifz din (safeguarding religion), by doing so that religious rules are implemented properly and correctly

Keywords: Trends, Halal Tourism and Living Qur'an.

\section{TREN WISATA HALAL SEBAGAI PRAKTIK LIVING QUR'AN}

\begin{abstract}
Abstrak - Tulisan ini membahas tentang wisata yang lazim dilakukan oleh setiap orang ke suatu tempat bukan untuk suatu pekerjaan, akan tetapi untuk melakukan kegiatan rekreasi. Tren wisata halal tidak hanya dipandang sebagai upaya untuk mengembangkan perekonomian suatu daerah, namun diupayakan juga konsep agar wisatawan Muslim nyaman pada saat melakukan kegiatan pariwisata, yaitu dengan menyediakan fasilitas ibadah yang memadai, ketersediaan air, sertifikat halal di setiap restoran dan hotel, pencegahan terhadap praktik asusila dan amoral, dan lain-lain. Fokus penelitian ini adalah bagaimana konsep pariwisata halal, faktor apa yang menyebabkan pariwisata halal terus dikembangkan, dan bagaimana pariwisata halal mempengaruhi keberagamaan dan peningkatan kesejahteraan suatu daerah. Dari penelitian ini ditemukan bahwa konsep wisata halal sangat urgen untuk terus dikembangkan karena merupakan praktik menghidupkan al-Qur'an atau living Qur'an dalam aktivitas pariwisata. Di samping itu, pariwisata halal juga merupakan langkah hifz din yaitu penjagaan terhadap agama, agar aturan-aturan agama tetap dilaksanakan dengan baik dan benar.
\end{abstract}

Kata Kunci: Tren, Wisata Halal dan Living Qur'an.

\section{PENDAHULUAN}

Pariwisata dunia mengalami berbagai perkembangan tren, salah satunya adalah pariwisata halal. Sejumlah negara di dunia berupaya mengembangkan industri pariwisata halal ini, yang halal ramah terhadap wisatawan Muslim. Negara yang memiliki penduduk mayoritas Muslim seperti Indonesia, UEA, dan Malaysia bersaing ketat untuk menarik wisatawan Muslim untuk menikmati wisata halal di negara tersebut. Tidak hanya di negara 
yang mayoritas Muslim, negara minoritas Muslim pun ikut mengembangkan konsep pariwisata halal, seperti di Jepang, Australia dan Inggris. Konsep yang disediakan adalah dengan memberikan fasilitas kebutuhan dasar yang diperlukan oleh wisatawan Muslim sesuai dengan hukum Islam ${ }^{1}$ yang tercantum dalam al-Qur'an dan hadis.

Sejauh ini kajian mengenai pariwisata halal sudah banyak dilakukan oleh para peneliti. Setidaknya ada tiga kecenderungan dalam kajian atas konsep pariwisata ini. Pertama, kajian tentang analisis terhadap pasar pariwisata halal yang ada di Indonesia. ${ }^{2}$ Kedua, kajian bagaimana strategi dalam membangun wisata halal. ${ }^{3}$ Ketiga, kajian tentang pro dan kontra pariwisata halal. ${ }^{4}$ Kajian yang menempatkan tren pariwisata halal studi living Qur'an merupakan satu kajian yang luput dari perhatian para peneliti.

Tulisan ini bertujuan untuk melengkapi literatur yang telah ditunjukkan di atas. Sejalan dengan hal itu, terdapat tiga pertanyaan yang dapat diajukan. Pertama, bagaimana konsep pariwisata halal? Kedua, faktor apa yang menyebabkan pariwisata halal terus dikembangkan? Ketiga, bagaimana pariwisata halal mempengaruhi keberagamaan dan peningkatan kesejahteraan suatu daerah?. Tiga pertanyaan tersebut akan menjadi fokus bahasan dalam artikel ini. Pertanyaan-pertanyaan di atas merefleksikan bagaimana mengekspresikan keberagamaan umat Islam dan bagaimana cara mereka menghidupkan alQur'an dalam mengembangkan pariwisata.

Penelitian ini termasuk library research (studi pustaka). Data primer penelitian ini diperoleh dari sumber utama yang menjadi pokok kajian penelitian yakni al-Qur'an. Adapun data sekunder diperoleh dari beberapa buku dan artikel yang berkaitan dengan pariwisata halal. Data-data yang diperoleh kemudian direduksi dan dikaitkan dengan pariwisata halal. Penggunaan judul tren pariwisata halal studi living Qur'an menjelaskan bahwa konsepkonsep yang dibangun dalam wisata halal merupakan praktik menghidupkan al-Qur'an.

\section{PEMBAHASAN}

\section{Konsep Pariwisata Halal}

Banyak istilah yang digunakan dalam menggambarkan aktivitas bepergian secara umum dalam al-Qur'an. Seperti ketika menggambarkan peristiwa Isra' Mi'raj, al-Qur'an menggunakan istilah "asra-yasri". 5 Dalam al-Qur'an juga disebut istilah "sayr" dalam mendeskripsikan aktivitas migrasi ${ }^{6}$ dan menggambarkan aktivitas bepergian dalam rangka

${ }^{1}$ Riska Destiana dan Retno Sunu Astuti, "Pengembangan Pariwisata Halal di Indonesia” Jurnal CoPAS, 01, no. 01 (2019).

2 Kurniawan Gilang Widagdyo, “Analisis Pasar Pariwisata Halal Indonesia” 1, no. 1 (2015): 8. Lihat juga: Fahadil Amin Al Hasan, "Penyelenggaraan Parawisata Halal di Indonesia (Analisis Fatwa DSN-MUI tentang Pedoman Penyelenggaraan Pariwisata Berdasarkan Prinsip Syariah)” 2 (2017): 20.

${ }^{3}$ Soraya Ratna Pratiwi, Susanne Dida, dan Nuryah Asri Sjafirah, "Strategi Komunikasi dalam Membangun Awareness Wisata Halal di Kota Bandung," Jurnal Kajian Komunikasi 6, no. 1 (29 Juni 2018): 78, https://doi.org/10.24198/jkk.v6il.12985. Lihat juga: Elpa Hermawan, "Strategi Kementerian Pariwisata Indonesia Dalam Meningkatkan Branding Wisata Halal" 7 (t.t.): 9. Lihat juga: Atie Rachmiatie dkk., "Strategi Komunikasi Pariwisata Halal Studi Kasus Implementasi Halal Hotel Di Indonesia Dan Thailand," Amwaluna: Jurnal Ekonomi dan Keuangan Syariah 4, no. 1 (1 Februari 2020), https://doi.org/10.29313/amwaluna.v4il.5256.

${ }^{4}$ Ghifari Yuristiadhi Masyhari Makhasi dan Muhammad Thohir Yudha Rahimmadhi, "Ramai-Ramai Menolak Wisata Halal: Kontestasi Politik Identitas Dalam Perkembangan Wisata Halal Di Indonesia," Jurnal Sosiologi Reflektif 14, no. 2 (24 April 2020): 373, https://doi.org/10.14421/jsr.vl4i2.1767.

${ }^{5}$ Lihat QS. Al-Isra (17): 1.

${ }^{6}$ Lihat QS. Al-Syu'ara (26): 52. 
mengambil hikmah atas peristiwa yang terjadi di masa lampau. ${ }^{7}$ Selain istilah sayr, al-Qur'an juga menggunakan "dharabtum fi al-ardh", 8 juga "intasyiru fi al-ardh" yang memiliki berjalan di muka bumi dengan maksud tertentu.

Dalam KBBI pariwisata adalah yang berhubungan dengan perjalanan untuk rekreasi, pelancongan dan turisme. ${ }^{10}$ Menurut Cooper pariwisata adalah aktivitas bepergian yang dilakukan oleh individu atau keluarga atau kelompok dari tempat tinggalnya ke tempat lain dengan tujuan melakukan kunjungan wisata bukan untuk melakukan suatu pekerjaan di tempat tujuan. Kunjungan bersifat sementara dan pada waktunya akan kembali ke tempat tinggal semula. ${ }^{11}$ Istilah halal berasal dari bahasa Arab yang berarti "diizinkan" atau "dibolehkan". Dalam KBBI kata halal diartikan diizinkan (tidak dilarang Syara'), yang diperoleh atau diperbuat dengan sah. ${ }^{12}$ Sedangkan dalam literatur Islam, istilah halal menunjukkan pada segala yang diajarkan dalam agama Islam dan menjadi landasan bagi perilaku dan kegiatan umat Islam. ${ }^{13}$ Konsep halal dalam Islam tidak hanya berkaitan dengan produk makanan atau minuman, melainkan semua aspek dalam kehidupan umat Islam. Konsep halal mengharuskan umat Islam agar hanya mengonsumsi produk yang diizinkan atau diperbolehkan oleh ajaran Islam, termasuk produk makanan, minuman, perbankan, pariwisata, kosmetik, pekerjaan dan lain-lain. ${ }^{14}$

Muhammad Munir Caudry, President Islamic Nutrition Council of Amerika menjelaskan wisata halal merupakan konsep baru pariwisata. Ini berbeda dengan wisata religi seperti umroh dan menunaikan ibadah haji. Wisata halal yaitu pariwisata yang melayani liburan, menyesuaikan gaya liburan dengan kebutuhan dan permintaan traveler muslim. ${ }^{15}$ Pariwisata halal juga didefinisikan sebagai seperangkat layanan tambahan yang mencakup amenitas, atraksi, dan aksesibilitas yang ditujukan dan diberikan untuk memenuhi pengalaman, kebutuhan, dan keinginan wisatawan Muslim yang disediakan oleh dunia usaha, masyarakat dan pemerintah. ${ }^{16}$

Ketersediaan kebutuhan dasar umat Muslim agar tetap menjalankan ibadah dan aktivitas sesuai dengan syari'at Islam selama berada di destinasi wisata merupakan konsep pariwisata halal. Mastercard Crescent Rating Global Muslim Travel Indeks 2019 menjelaskan kebutuhan dasar wisatawan Muslim saat berwisata, di antaranya:

a. Makanan halal. Sertifikat halal makanan dan minuman yang dapat diidentifikasi oleh wisatawan Muslim, karena hal tersebut merupakan kunci untuk mengurangi keraguan dalam mengkonsumsi makanan dan minuman di destinasi wisata setempat.

\footnotetext{
${ }^{7}$ Lihat QS. Al-Hajj (22): 69.

${ }^{8}$ Lihat QS. An-Nisa (4): 101.

${ }^{9}$ Lihat QS. Al-Jumu'ah (62): 9.

${ }^{10}$ Lihat: https://kbbi.web.id/pariwisata, diakses pada tanggal 20 November 2020 pada pukul 10.00 Wita.

11 Samsuduha Samsuduha, "Wisata Halal Sebagai Implementasi Konsep Ekonomi Syariah," Al-Tafaqquh: Journal of Islamic Law 1, no. 1 (5 Agustus 2020): 22, https://doi.org/10.33096/altafaqquh.vlil.13.

12 Lihat: https://kbbi.web.id/halal, diakses pada tanggal 20 November 2020 pada pukul 14.00 Wita.

${ }^{13}$ Aan Jaelani, "Halal Tourism Industry in Indonesia: Potential and Prospects," SSRN Electronic Journal, 2017, https://doi.org/10.2139/ssrn.2899864.

${ }^{14}$ Lufi Wahidati dan Eska Nia Sarinastiti, "Perkembangan Wisata Halal Di Jepang” 1, no. 1 (2018): 11.

15 Jaelani, "Halal Tourism Industry in Indonesia."

16 https://www.kemenparekraf.go.id/post/siaran-pers-kemenpar-siapkan-pedoman-wisata-halal-diindonesia. Diakses pada tanggal 24 November 2020, pukul 22.54 WITA.
} 
b. Fasilitas ibadah. Penyediaan fasilitas ini sangat penting untuk pemenuhan aktivitas ibadah wajib sholah 5 waktu umat Muslim. Wisatawan Muslim membutuhkan ruang beribadah dengan arah petunjuk kiblat dan tempat berwudhu.

c. Kamar mandi dengan fasilitas kran air, hal ini sangat dibutuhkan wisatawan Muslim untuk bersuci.

d. Tidak ada sentimen Islamofobia, wisatawan Muslim membutuhkan jaminan keamanan dan keselamatan di tempat wisata.

e. Pengalaman berwisata berkaitan dengan kehidupan Muslim, seperti pengalaman unik yang berkaitan dengan budaya dan identitas Muslim, misalnya situs kebudayaan Islam atau berinteraksi dengan komunitas Muslim lokal.

f. Fasilitas rekreasi yang privat, yaitu memberikan privasi untuk pria dan wanita.

g. Tidak ada pelayanan non-halal, menghindari fasilitas yang menyediakan minuman beralkohol.

Pengembangan pariwisata halal di Indonesia khususnya dilakukan dengan upaya meningkatkan keberadaan hotel syari'ah, sertifikat halal oleh LPPOM MUI, sinergi dengan banyak pihak (kerjasama dengan dewan syari'ah, Majelis Ulama Indonesia dan Lembaga Sertifikasi Usaha), pelatihan SDM, sosialisasi, capacity building, serta mempromosikan wisata halal ke dunia Internasional. Wisata halal bersifat inklusif bagi semua wisatawan dengan mengutamakan prinsip-prinsip syari'ah dalam menyelenggarakan pariwisata dan pelayanan yang ramah bagi wisatawan baik Muslim atau non Muslim.

Indonesia mengkonseptualisasikan pariwisata halal dengan lebih baik. Kementerian pariwisata dan Dewan Syari'ah Nasional Majelis Ulama Indonesia (DSN-MUI) menetapkan sembilan indikator yang menjadi acuan pariwisata halal di Indonesia. Beberapa indikator itu, antara lain: orientasi keuntungan bagi masyarakat; orientasi pada penyegaran dan ketenangan; pencegahan terhadap aktivitas kesyirikan dan tahayul; pencegahan terhadap aktivitas asusila dan tidak bermoral; penjagaan terhadap perilaku, etika dan nilai-nilai kemanusiaan; penjagaan terhadap kepercayaan, keamanan dan kenyamanan; universalitas dan inklusifisme; perlindungan terhadap lingkungan dan penghormatan terhadap nilai-nilai sosial, budaya dan kearifan lokal. ${ }^{17}$

Menurut Menteri Pariwisata Arief Yahya, ada lima dari sepuluh titik wisata hahal terbaik dunia, di antaranya, Lombok, Aceh, Riau dan kepulauan Riau, Jakarta dan Sumatra Barat. Kelima tempat destinasi tersebut didukung restoran bersertifikat dan memanjakan wisatawan Muslim dengan berbagai fasilitas pendukung. Kebijakan tentang pariwisata halal di Indonesia tidak termuat sama sekali dalam UU No. 10 Tahun 2009 tentang kepariwisataan. Kebijakan pariwisata halal justru ditemukan dalam peraturan daerah provinsi Nusa Tenggara Barat (NTB) No. 2 Tahun 2016. ${ }^{18}$ Perda ini merupakan respons daerah terhadap perkembangan global dalam tata kelola dunia wisata.

\section{Pariwisata Halal sebagai Praktik Living Qur'an}

Konsep pariwisata halal tidak hanya menunjukkan pariwisata sebagai sektor yang memberikan keuntungan secara material, akan tetapi juga bernilai intrinsik, yang tentunya

\footnotetext{
17 Surwandono Surwandono dkk., "Polemik Kebijakan Wisata Halal di Indonesia serta Tinjauannya dalam Maqashid Syariah," TSA2AFAH 16, no. 1 (3 Mei 2020): 91, https://doi.org/10.21111/tsaqafah.vl6il.3594.

18 "LD Perda No 2 Th 2016.pdf," t.t. 
relevan dengan perintah dan anjuran yang ada dalam al-Qur'an. konsep pariwisata halal dikembangkan agar aktivitas yang menjadi keharusan atau kewajiban bagi orang Muslim tetap berlangsung sesuai dengan ajaran agama.

Peneliti menemukan ada beberapa faktor teologis berdasar dari al-Qur'an yang menjadi faktor utama dalam mengembangkan pariwisata halal, di antaranya:

1. Perintah memakan makanan halal. Dalam al-Qur'an terdapat ayat yang memerintahkan untuk mengkonsumsi makanan yang halal:

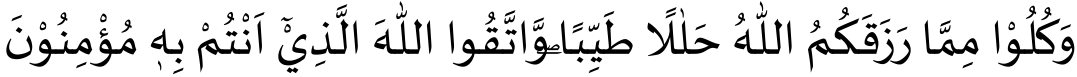

"Dan makanlah dari apa yang telah diberikan Allah kepadamu sebagai rezeki yang halal dan baik, dan bertakwalah kepada Allah yang kamu beriman kepada-Nya." (QS. Al-Maidah: 88)

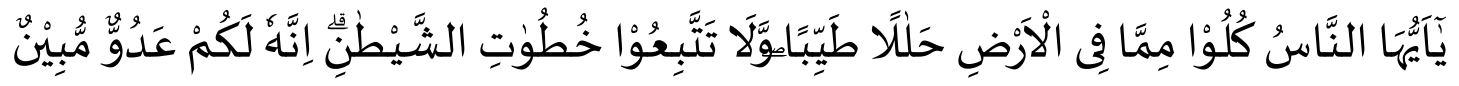

Wahai manusia! Makanlah dari (makanan) yang halal dan baikyang terdapat di bumi, danjanganlah kamu mengikuti langkah-langkah setan. Sungguh, setan itu musuh yang nyata bagimu. (QS. alBaqarah: 168).

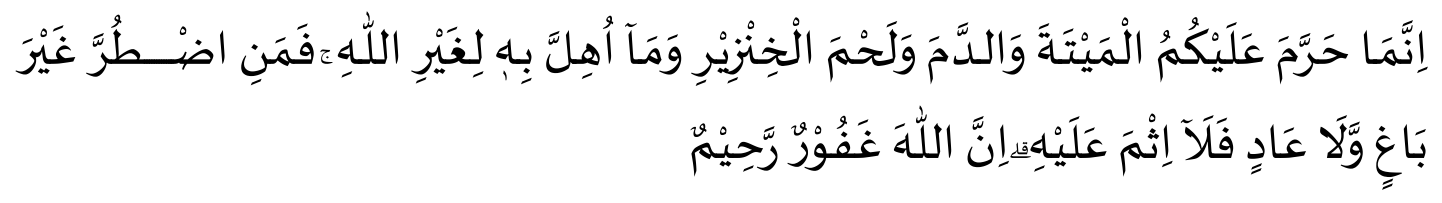

"Sesungguhnya Dia hanya mengharamkan atasmu bangkai, darah, daging babi, dan (daging) hewan yang disembelih dengan (menyebut nama) selain Allah. Tetapi barangsiapa terpaksa (memakannya), bukan karena menginginkannya dan tidak (pula) melampaui batas, maka tidak ada dosa baginya. Sungguh, Allah Maha Pengampun, Maha Penyayang." QS. Al-Baqarah: 173.

2. Fasilitas ibadah yang memadai, seperti masjid atau mushalla sebagai tempat melaksanakan ibadah shalat. Salah satu yang menunjukkan urgensi shalat adalah pengkhususan masjid sebagai tempat pelaksanaannya, ${ }^{19}$

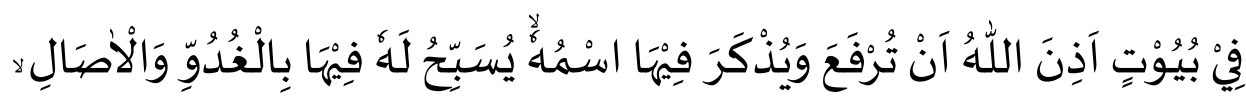

"(Cahaya itu) di rumah-rumah yang di sana telah diperintahkan Allah untuk memuliakan dan menyebut nama-Nya, di sana bertasbih (menyucikan) nama-Nya pada waktu pagi dan petang." QS. An-Nur: 36

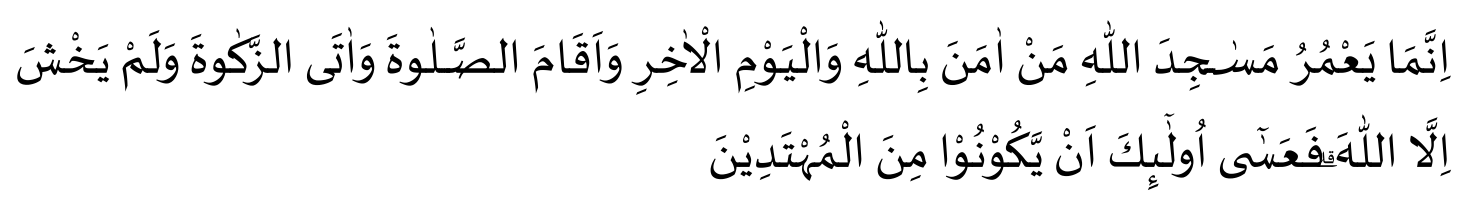

"Sesungguhnya yang memakmurkan masjid Allah hanyalah orang-orang yang beriman kepada Allah dan hari kemudian, serta (tetap) melaksanakan salat, menunaikan zakat dan tidak takut (kepada apa pun) kecuali kepada Allah. Maka mudah-mudahan mereka termasuk orang-orang yang mendapat petunjuk." QS. At-Taubah.

${ }^{19}$ Ali Abul al-Bashal, Rukhsah dalam Shalat Keringanan-keringanan Shalat dalam Kondisi Tidak Biasa (T.T: Dar ul Furqan, 2011)., $\mathrm{x}$. 
3. Jaminan terhadap akidah, QS. Al-Kafirun: 6.

$$
\text { لَكُمْمَ دِيْنُكُمْ وَلِيَ دِيْنِ }
$$

"Untukmu agamamu, dan untukku agamaku."

4. Perlindungan dari tindakan fahsya' atau asusila, QS. Al-Nur: 21.

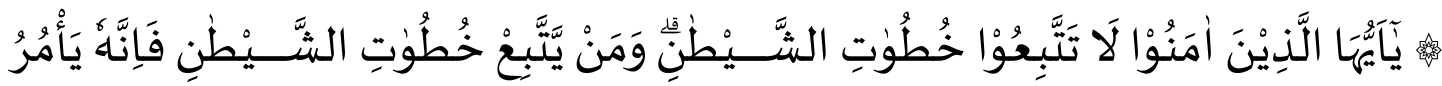

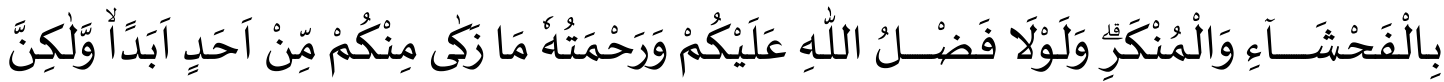

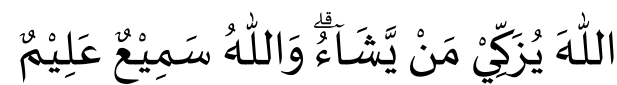

"Wahai orang-orang yang beriman! Janganlah kamu mengikuti langkah-langkah setan. Barangsiapa mengikuti langkah-langkah setan, maka sesungguhnya dia (setan) menyuruh mengerjakan perbuatan yang keji dan mungkar. Kalau bukan karena karunia Allah dan rahmat-Nya kepadamu, niscaya tidak seorang pun di antara kamu bersih (dari perbuatan keji dan mungkar itu) selama-lamanya, tetapi Allah membersihkan siapa yang Dia kehendaki. Dan Allah Maha Mendengar, Maha Mengetahui."

5. Perlindungan keamanan jiwa dan kepemilikan serta kelestarian lingkungan, QS. Al-Rum: 41-42.
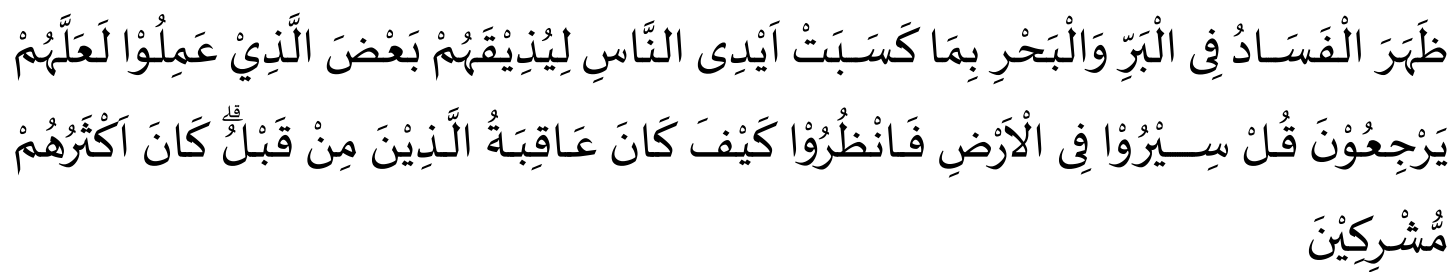

"Telah tampak kerusakan di darat dan di laut disebabkan karena perbuatan tangan manusia; Allah menghendaki agar mereka merasakan sebagian dari (akibat) perbuatan mereka, agar mereka kembali (ke jalan yang benar). Katakanlah (Muhammad), "Bepergianlah di bumi lalu lihatlah bagaimana kesudahan orang-orang dahulu. Kebanyakan dari mereka adalah orang-orang yang mempersekutukan (Allah)."

6. Inklusifisme, QS. Al-Hujarat: 13.

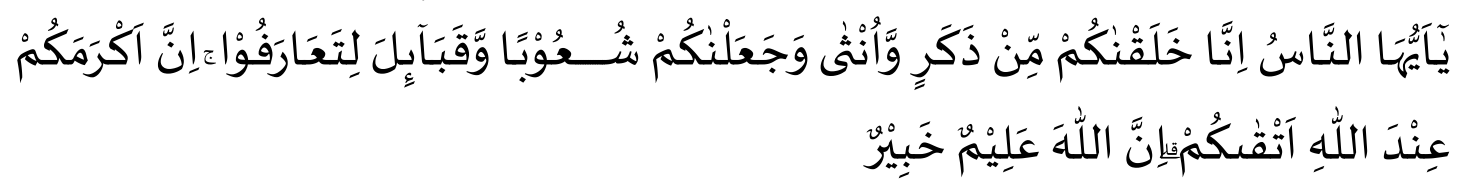

"Wahai manusia! Sungguh, Kami telah menciptakan kamu dari seorang laki-laki dan seorang perempuan, kemudian Kami jadikan kamu berbangsa-bangsa dan bersuku-suku agar kamu saling mengenal. Sesungguhnya yang paling mulia di antara kamu di sisi Allah ialah orang yang paling bertakwa. Sungguh, Allah Maha Mengetahui, Mahateliti."

Berdasarkan beberapa dalil-dalil al-Qur'an yang menjadi landasan di atas, konsep pariwisata halal menjadi sangat urgen untuk terus dikembangkan karena merupakan praktik menghidupkan al-Qur'an atau living Qur'an dalam aktivitas pariwisata. 


\section{Implikasi Pariwisata Halal}

Konsep halal dalam agama Islam tidak hanya berkaitan dengan produk makanan atau minuman, bahkan segala aspek dalam kehidupan orang Islam baik laki-laki maupun perempuan. Hal ini mengharuskan umat Islam agar hanya mengonsumsi produk yang diizinkan dalam agama, termasuk produk makanan/minuman, perbankan dan finansial, pariwisata, kosmetik, pekerjaan dan lain-lain. ${ }^{20}$ Asazuma menjelaskan wisata halal ini merupakan konsep baru industri pariwisata yang menawarkan paket dan tujuan wisata yang didesain untuk melayani kebutuhan wisatawan Muslim. ${ }^{21}$

Adanya tren pariwisata halal memberi pengaruh besar dalam bidang ekonomi, seperti pariwisata halal yang dikembangkan oleh Kementerian Pariwisata RI sejak tahun 2015. Pasar wisata halal mengalami pertumbuhan pada tahun 2018 mencapai 18\% dengan jumlah wisatawan Muslim mancanegara yang berkunjung ke destinasi wisata halal prioritas Indonesia mencapai 2,8 juta dengan devisa mencapai lebih dari 40 triliun. ${ }^{22}$ Dengan ini bisa kita lihat bahwa pariwisata halal dapat meningkatkan perekonomian masyarakat yang ada di wilayah-wilayah potensial destinasi wisata. Meningkatnya kunjungan wisatawan dari tahun ke tahun berimplikasi positif pada perekonomian suatu daerah hingga negara.

Jika dilihat perspektif living Qur'an, dapat dikemukakan bahwa wisata halal berimplikasi pada:

1. Meningkatkan ketaatan kepada Allah SWT. karena dalam praktiknya pariwisata halal menyediakan fasilitas ibadah untuk memudahkan wisatawan beribadah kepada Allah.

2. Menguatkan iman dan ketaqwaan kepada Allah SWT. karena dalam praktiknya wisata halal harus bebas dari praktik riba.

3. Membentuk karakter yang Islami karena harus jauh dari perbuatan fahsya' dan asusila.

4. Menjaga diri dari makanan atau minuman yang diharamkan oleh agama.

Dikemukakan oleh Qardhawi, dengan memuat nilai-nilai ajaran Islam (khususnya alQur'an), perekonomian Islam diyakini akan mampu mensejahterakan umat manusia dengan lebih baik. Dengan demikian dapat disimpulkan, bahwa wisata halal merupakan praktik living Qur'an, yaitu menghidupkan nilai-nilai yang terkandung dalam al-Qur'an pada konsep pariwisata halal. Selain itu juga, pariwisata halal merupakan langkah hifz din (menjaga agama), seperti mengkonsumsi makanan halal merupakan perintah Allah secara langsung, demikian juga perintah shalat. Kedua hal tersebut tidak boleh ditinggalkan oleh orang Muslim di manapun ia berada, oleh karena itu dengan adanya pariwisata halal ini memudahkan wisatawan Muslim khususnya untuk tetap melaksanakan apa yang diperintahkan agama melalui al-Qur'an. Pariwisata halal tidak hanya menjawab kebutuhan duniawi, namun mampu juga memenuhi kebutuhan akhirat karena bernilai secara Islami.

${ }^{20}$ Hatem El-Gohary, "Halal Tourism, Is It Really Halal?," Tourism Management Perspectives 19 (Juli 2016): 12430, https://doi.org/10.1016/j.tmp.2015.12.013.

21 Asazumi Takumi, "Halal Industri Activates Japanese Tourism Market,". Retrieved from: http://human.kanagawa-u.ac.jp/gakkai/student/pdf/ill/110320.pdf.

${ }^{22}$ Riska Destiana dan Retno Sunu Astuti, "Pengembangan Pariwisata Halal di Indonesia." 


\section{KESIMPULAN}

Pariwisata adalah aktivitas bepergian yang dilakukan oleh individu atau keluarga atau kelompok dari tempat tinggalnya ke tempat lain dengan tujuan melakukan kunjungan wisata. Adapun konsep wisata halal merupakan konsep baru pariwisata. Pariwisata halal yaitu pariwisata yang melayani liburan, menyesuaikan gaya liburan dengan kebutuhan dan permintaan traveler muslim. Proses berwisata dalam pariwisata halal dilakukan berdasarkan ajaran Islam. Konsep yang diterapkan dalam pariwisata halal merupakan praktik menghidupkan al-Qur'an. Ini terlihat dari semua konsep yang dibangun relevan dengan apa yang diperintahkan oleh Allah SWT. di dalam al-Qur'an. Berdasarkan beberapa dalil-dalil alQur'an yang menjadi landasannya, konsep pariwisata halal menjadi sangat urgen untuk terus dikembangkan karena merupakan fenomena menghidupkan al-Qur'an atau living Qur'an dalam aktivitas pariwisata. Selain praktik living Qur'an, pariwisata halal juga merupakan langkah hifz din yaitu penjagaan terhadap agama agar aturan-aturan agama tetap dilaksanakan dengan baik dan benar. Dengan adanya sertifikat halal pada restoran dan hotel, wisatawan Muslim terhindar dari makanan yang diharamkan oleh Allah SWT dalam al-Qur'an. begitu juga dengan adanya fasilitas ibadah yang memadai, wisatawan Muslim bisa melaksanakan shalat setiap waktunya dengan aman dan nyaman. 


\section{DAFTAR PUSTAKA}

Ali Abul al-Bashal. Rukhsah dalam Shalat Keringanan-keringanan Shalat dalam Kondisi Tidak Biasa. T.T: Dar ul Furqan, 2011.

Asazumi Takumi. "Halal Industri Activates Japanese Tourism Market," t.t.

El-Gohary, Hatem. "Halal Tourism, Is It Really Halal?" Tourism Management Perspectives 19 (Juli 2016): 124-30. https://doi.org/10.1016/j.tmp.2015.12.013.

Hasan, Fahadil Amin Al. "Penyelenggaraan Parawisata Halal di Indonesia (Analisis Fatwa DSN-MUI tentang Pedoman Penyelenggaraan Pariwisata Berdasarkan Prinsip Syariah)" 2 (2017): 20.

Hermawan, Elpa. "Strategi Kementerian Pariwisata Indonesia Dalam Meningkatkan Branding Wisata Halal" 7 (t.t.): 9.

https://kbbi.web.id/pariwisata

https://kbbi.web.id/halal

https://www.kemenparekraf.go.id/post/siaran-pers-kemenpar-siapkan-pedoman-wisata-halal-diindonesia

Jaelani, Aan. "Halal Tourism Industry in Indonesia: Potential and Prospects." SSRN Electronic Journal, 2017. https://doi.org/10.2139/ssrn.2899864.

"LD Perda No 2 Th 2016.pdf," t.t.

Makhasi, Ghifari Yuristiadhi Masyhari, dan Muhammad Thohir Yudha Rahimmadhi. "Ramai-Ramai Menolak Wisata Halal: Kontestasi Politik Identitas Dalam Perkembangan Wisata Halal Di Indonesia." Jurnal Sosiologi Reflektif 14, no. 2 (24 April 2020): 373. https://doi.org/10.14421/jsr.vl4i2.1767.

Pratiwi, Soraya Ratna, Susanne Dida, dan Nuryah Asri Sjafirah. "Strategi Komunikasi dalam Membangun Awareness Wisata Halal di Kota Bandung." Jurnal Kajian Komunikasi 6, no. 1 (29 Juni 2018): 78. https://doi.org/10.24198/jkk.v6il.12985.

Rachmiatie, Atie, Rahma Fitria, Karim Suryadi, dan Rahmat Ceha. "Strategi Komunikasi Pariwisata Halal Studi Kasus Implementasi Halal Hotel Di Indonesia Dan Thailand.” Amwaluna: Jurnal Ekonomi dan Keuangan Syariah 4, no. 1 (1 Februari 2020). https://doi.org/10.29313/amwaluna.v4il.5256.

Riska Destiana dan Retno Sunu Astuti. "Pengembangan Pariwisata Halal di Indonesia" 01, no. 01 (2019).

Samsuduha, Samsuduha. "Wisata Halal Sebagai Implementasi Konsep Ekonomi Syariah." Al-Tafaqquh: Journal of Islamic Law 1, no. 1 (5 Agustus 2020): 20. https://doi.org/10.33096/altafaqquh.vlil.13.

Surwandono, Surwandono, Rizki Dian Nursita, Rashda Diana, dan Ade Meiliyana. "Polemik Kebijakan Wisata Halal di Indonesia serta Tinjauannya dalam Maqashid Syariah.” TSA2AFAH 16, no. 1 (3 Mei 2020): 9l. https://doi.org/10.2111l/tsaqafah.vl6il.3594.

Wahidati, Lufi, dan Eska Nia Sarinastiti. "Perkembangan Wisata Halal Di Jepang” 1, no. 1 (2018): 11.

Widagdyo, Kurniawan Gilang. “Analisis Pasar Pariwisata Halal Indonesia” 1, no. 1 (2015): 8. 